\title{
The Exploration and Practice of Surveying Course Teaching Reform
}

\author{
Wei Li \\ School of civil engineering \\ University of science and technology Liaoning \\ Anshan,China \\ ln_as_lw@126.com \\ Liangbo Gao \\ School of civil engineering \\ University of science and technology Liaoning \\ Anshan,China \\ 122180377@qq.com
}

\author{
Chang Wang \\ School of civil engineering \\ University of science and technology Liaoning \\ Anshan,China \\ 280304727@qq.com
}

\begin{abstract}
Great changes of geomatics equipment and the development of geomatics science and technology propose higher requirements on geomatics teaching. Under the new situation, this paper analyzes status and nature and problems in teaching of the existing surveying of non-surveying and mapping, proposing the feasibility measure of the reform of geomatics teaching. For example, carrying on the adjustment of teaching content, strengthening practice teaching, enriching teaching methods and means, reforming examination method and so on.
\end{abstract}

Keywords-component; geomatics; teaching methods; teaching content; teaching reform

\section{INTRODUCTION}

Civil engineering surveying, geomatics, road construction survey and other courses are professional foundation courses that major students must learn, which includes architecture, civil engineering and architectural environment and equipment engineering, mineral resources engineering, traffic engineering and so on. Periods are about 40 class hours, in addition to , there is another one to two weeks of concentrated teaching practice .

In recent years, it changes the face of the geomatics industry with the increasing development of 3 s techno loge and makes instrument of surveying and mapping, new theories, new technologies and new methods develop rapidly. In addition to, it brings strong impact on traditional surveying and mapping. Traditional survey course teaching cannot adapt to the needs of modern surveying and mapping production. How to make measurements reasonably and practicably on the teaching reform of the course of study is a surveying education topic that deserves urgent discussion in colleges and universities

\section{NATURE OF THE COURSE AND STATUS}

There are more than 400 colleges and universities nationwide offering surveying courses that include over more than 20 professional courses in China according to the statistics of Chinese society of surveying and mapping Education Research Council. The overall objective of surveying teaching: enable students to grasp the basic theory and basic of geospatial information collection methods and understand application of new surveying technology in the professional field. Due to professional differences, geomatics status is different in different professions. Civil, architectural environment and equipment engineering, architectural and other professions focuses on large scale topographic mapping and applications, setting-out survey course content, judging from the professional nature, while mineral resources engineering, traffic engineering and other professions focuses on topographic map applications, the $3 \mathrm{~S}$ technology and other mapping technologies.

The survey course in the curriculum is a professional Foundation course, and it is the basic supporting discipline used for other course study and solving major practical problems related to measurement. Considered from the various professional course system as a whole, surveying as a specialized courses has its independence, and services on the relevant professional courses, Therefore, surveying teaching must combine with professional training objective and arrange measuring connection reasonably between teaching and related courses to enable students to master the fundamentals of surveying and mapping, and students should be familiar with application of modern surveying and mapping technology to solve actual problems in production and scientific research on top of the basic skills .

\section{PROBLEMS IN TEACHING}

Firstly, the teaching materials are old, and most of the teaching materials and chapter structure for decades have not much updating. Although new theories, new technologies and new equipment are presented in the materials, it ignores the "three new" on reform of the teaching materials and teaching requirements.

Secondly, teaching means are single and have no innovation. Traditional expository teaching that is that teachers tell something and students listen does not fit strong practice of 
surveying courses because it makes students understand when they are listening while confuse when they practice.

The teaching content and professional development goals are not close without highlighting the teaching goals, which makes various surveying courses in specialty of teaching content identical.

Lastly, experiment and practice teaching are weak. Surveying is a practical and applied a strong discipline. In the learning process, we must get through practice to truly understand and master and use it. "No" does not meets educational purposes, which leads students cannot reasonably use knowledge to solve real-world problems in practical work. Most restrictions are due to the conditions of teaching in colleges and universities. Used instruments are mostly obsolete and backward, which is far from modern production demands and not conducive to cultivate students ' practice ability the detriment of students ' practical ability of students. Many universities are often looked down upon construction of the experiment base, resulting in measurement practice problems. In some schools there is no established experimental internship database, students ' experimental practice is arbitrary, discourage teachers on students ' experimental inspection of the internship.

\section{TEACHING REFORMS}

Following the General guidelines of school teaching reform, based on "reinforcing the basic theory, basic knowledge and basic skills training, and taking into account the application of new technology of surveying and mapping" principles, we developed a new teaching plan. The basic goal is giving traditional measurement techniques and setting out the basic theory and basic methods to students, and appropriate application of new instruments and new technologies.

\section{A. Identifying the Emphasis of Lecture Content}

Non-measurement of surveying course in specialty of objects in our school architecture, civil engineering and construction environment and device engineering, mineral resources engineering, traffic engineering and professional requirements are different .For different students, in determining the lectures are focused on. For the students in civil engineering and architecture, in addition to teaching traditional content, such as the standard of measurement, angle measurement, distance measurement, the need to focus on building construction Lofting axis setting out . Students that major in building environment and facilities engineering, pipeline lofting is that they focus to mineral resources engineering students, and mine survey is a learning focus, students majoring in transportation and road engineering survey are a learning focus.

\section{B. Development of Practical Materials}

Original surveying teaching contents, methods and standards are unable to adapt to the development of science and technology of surveying and mapping, the traditional mode of education and training cannot meet social demand for technical personnel of surveying and mapping .In addition to teaching basic knowledge, basic theories and basic method ,student should also increase the emerging, practical knowledge of surveying, global positioning systems, digital integration of modern surveying and mapping techniques such as mapping and GIS basics. Forming the required knowledge and ability structure of training goals, cultivating capable to integrated applications of information technology of surveying and mapping, and students, to accommodate future social needs

Based on the research, combining the training goals and learning needs, eliminating the original surveying textbook, prepared, adapted to the needs of various professional surveying and mapping production, in line with the new situation of the new textbooks, students learn content and technological developments.

\section{Selecting Course Content}

Non-surveying and mapping majors before surveying textbook chapters is Traditional measured content ,such as leveling, angle measurement, and distance measurement and so on, which enables students to master certain skills. Later chapters of textbooks include construction surveying, road surveys, pipeline surveying, mine surveying, as well as new theories, new technologies and new equipment, which can be selected according to the needs of the professional teaching

\section{Strengthening Practice Teaching}

Strong survey course practice, and practice teaching is an effective way to cultivate students ' practice ability, measurement of course indispensable for important links, which includes a class experiment and focused practice

Professional surveying experimental 6 10 hours, which aims to provide students with theoretical courses, exercise ability to manipulate instruments. Up as advocated teaching practice and stress students to prepare before class and after class and write laboratory, internship reports. Measurement, angle measurement, distance measurement, standards setting out chapters on teaching content reform in practical teaching to complete, students generally reflect the images, an intuitive, perceptual, and good results.

Combine with surveying and development of timely purchases of new equipment, in measurement in teaching so that students come to understand, and experiments planned, purposeful arrangement in practice to enable students to quickly adapt to the technological development of surveying and mapping needs.

There is 1-2-week concentrated practice time. Class talking about various elements combined with a measuring instrument practice, deepen understanding and ability to learn content, enhance team spirit and improve their comprehensive ability and innovative consciousness. Establish a stable base for teaching practice in schools, wires and leveling in the past internship sites, based on establishment of total stations, GPS and other modern equipment for on-campus practice teaching base, laying permanent planar and vertical control network in schools, the establishment of plane coordinate and elevation database for a large number of observation points, which can

Effectively organize internships to ensure quality and effectiveness. 


\section{ENRICHING TEACHING METHODS AND MEANS}

Teaching pattern shifts from injection to the heuristic .Requirements based on objective laws of teaching in the teaching of teachers, continuing to effectively stimulate students ' interest in learning and knowledge, so that students ' thinking and intelligence is always active, so as to give full play to the initiative and enthusiasm, to students of the consciousness, independent thinking, knowledge and skills at the same time, developing intelligence, learning to learn

Based on the above requirements, featured content, wellorganized instruction to brilliantly describe causes and effects of the problems for knowledge, profound analysis, practice pictures from inspired professors in terms of knowledge, ask questions and discuss with each other and leave appropriate space of thinking for students and allow students to think independently

Teaching methods convert to modern transition. Encourage teachers to enhance CAI references to modern teaching methods, to diversify teaching content of presentation and delivery methods. Using multimedia technology, collection of animation, text, pictures, sounds, for one, make the course content in conjunction with other forms of instruction; greatly improve the efficiency and effectiveness of education.

\section{REFORM OF CURRICULUM EVALUATION}

Reform of curriculum evaluation mode can better meet teaching requirements and reflect the students ' learning levels. Full score of 100 , theory test $70 \%$ per cent of total score, GPA score of $30 \%$, an overall score of 60 or more (including 60 minutes) for the exam . GPA contain experiments, homework, quizzes, questions and other components. Compared with the past, and it has increased the percentage of experimental operation in General and emphasis more on assessment of students ' practical abilities, thus highlighting the characteristics of strong surveying practice.

Survey course of the semester is with closed book examination for theory examination.

Original exam was too simple, conceptual, and not relevant to the student's professional requirements. After the exam reform, increasing the practical exam, and the focus of attention for various disciplines of surveying, as to civil engineering students, stepped up in the exam by graph type and setting out the topic.

\section{CONCLUDING REMARKS}

New training objectives and lesson plans on the basis of new professional directory in countries are necessary and timely to reform the teaching of surveying of non-surveying profession. Only this way can meet the needs of educational reform in colleges and universities and develop applicationoriented talents there are many things to do about the measurement of non-surveying and mapping majors' courses reform. I believe that teaching and teaching quality will be even greater progress with the continuous improvement of teaching conditions and continuous improvement of teacher quality.

\section{REFERENCES}

1] Deng Caihua, Chen Zhengyang, Liu Qingyuan , Non-geomatics specialty 《geomatics》 my opinion on the reform of teaching methods [j]. mine surveying 2005(1),16-18

[2] Wang Tiesheng, Zhang Bing, Zhou Jianye, Liu Min ,Reform of nonsurveying practice for surveying and exploration [j]. mine survey, (2006), 22-24.

[3] Liang Jianchang, Du Jiangang, Yang Tengfeng, Discussion on teaching method of the surveying of non-surveying and mapping majors courses [j]. vocational education research, 2006 (2), 14-16

[4] Suo Junfeng. Design and construction of the measurement of nonsurveying and mapping majors practice base, 2008(5), 18-21.

[5] Xu Lihua, experimental and practical teaching reform for surveying in non-geomatics specialty [j] Journal of Chongqing University of science and technology (Social Science Edition) (2008), 26-30.

[6] Yang Li, Wang Yuzhen .High vocational teaching reform of surveying of non-surveying and mapping major exploration [j]. 2010,09 of science and technology in Western China (10), 10-14.

[7] Liang Xinmei, Hu Youjian, Chen Gang. Discussion on teaching reform of surveying of non-surveying and mapping specialty [j]. 2008,6 geospatial information (4), 4-6. 